\title{
1. Issues and Overview
}

\author{
Shiro Armstrong and Aaron Batten \\ Crawford School of Economics and Government, \\ The Australian National University
}

Human capital plays a key role in the development of all economies. A decade ago, discussions of education and development tended to be categorised by focusing on the importance of primary and secondary services. For example, it was thought more important to teach large amounts of people to read than to teach a small cadre liberal arts and high-level sciences. In an egalitarian sense, support for universities was seen as biased against poorer elements of society. These arguments have a degree of merit and, certainly, primary and secondary education are both important elements of the sector - not least because they feed directly into the quality of higher levels of education. But the lessons of recent economic history also highlight both the importance of strong higher educational outcomes obtained through universities and the need for delivering substantial economic support. The growth of Europe and the United States in particular can be attributed largely to the success of their universities. These knowledge-based economies require high levels of human capital, which influences a large number of economic outcomes and boosts long-term productivity. The current world economy is going to be increasingly dominated by knowledge-based industries over the coming decades. Agricultural, industrial and technical revolutions will all give way to increases in knowledge. Manufactures will continue to be displaced by services, and salary differences between knowledge-based and non-knowledge-based industries will continue to rise. The widening of these economic differentials highlights the importance of investing in knowledge and getting the fundamentals of each country's higher education sector right.

These developments are also placing increasing pressure on governments across the globe as citizens increase their demand for higher levels of human capital so that they can benefit from the growing knowledge-based economy. In addition, the constraints on investment in higher education within the region are in nearly all cases large. As such, the benefits must be weighed carefully against the large costs associated with a quality higher education sector-particularly in developing countries with tight fiscal constraints.

At present, the United States clearly dominates the university sector, and Lawrence Summers in Chapter 2 offers some important insights into how the sector should be run. First, the US university sector is intensely competitive- 
as universities compete for the best students, faculty and rankings. This can sometimes be destructive but the fact of brutal competition forces a discipline and excellence that are present in US universities and not present in many other countries. Too often countries try too carefully to plan and manage their university sector, which undermines the sector's ability to drive for excellence. The second element is a governance model that maintains 'diamonds'. Judgments about the quality of staff and students are best made by experts in the field, but this can often lead to the self-perpetuation of ideas. It is difficult, for example, for incumbents to shut down mediocre activities and support ideas that diverge from their own. The challenge therefore is to draw on experts for identifying resources but to also maintain diversity.

The third great strength of the US system is its reliance on the private sector. The greatest universities are not public institutions, as the lion's share of resources comes from successful alumni. This mixture between the public and the private sector is a great stimulus to innovation within the university sector. Asia has the potential to build on these US lessons. As its wealth grows, so too does it ability to build universities that challenge the dominance of US universities and enhance the long-term development prospects of the region.

Ultimately, financing higher education systems must be focused on providing wide-scale access to higher education that is based on merit rather than economic status. Substantial efforts are required to attract the best students regardless of their life circumstances. This can act to help transform a society. Higher education is, however, about much more than simply teaching students technical skills. A quality higher education system must also be able to train students to question traditional dogma and assess views based on the strength of the argument rather than the person who is delivering it or what their status is in society. Fostering this type of environment, which challenges the current status quo, is a key role for quality universities as it promotes long-term improvements in entrepreneurship and productivity.

Higher education financing systems should thus aim to improve all aspects of higher education delivery. In all countries, this should include increasing both the quality and the quantity of access, helping to smooth consumption over time for consumers of higher education, and perhaps, most importantly, to widen access to those who are disadvantaged. 


\section{The Economics of Higher Education and its Financing Arrangements}

Economic theory offers a number of lessons for a system that seeks to strengthen the quality of higher education while simultaneously promoting access. At present, access to higher education within East Asia is growing swiftly. This is a positive development. The expansion of access to higher education is, however, occurring largely through the expansion of the private sector. This is creating a number of challenges to the future dynamism of the sector. For example, private financing might preclude the enrolment of deserving students who do not have the ability to pay, and often evokes resentment among students who do. In Chapter 3, Nicholas Barr sets out the principles - from theory and practice - by which policy makers can make decisions regarding access to higher education and the growth of private and public institutions and address challenges of equity.

The economic case for government subsidies in the higher education sector is based largely on the large positive externalities involved in higher education. Market failure occurs because private-sector lending to finance tuition and prospective students' smooth consumption are unreliable, as banks are unable to generate collateral on human capital. This leads to suboptimal rates of borrowing and lending and, in the absence of government intervention, suboptimal levels of investment in higher education.

There are, however, a number of principles that must be incorporated into the system if government intervention into the higher education sector is to be effective at meeting its objectives. Barr gives lessons for policy design from economic theory combined with operational experiences. The first of these is that competition within all areas of the sector is highly beneficial, as the US case highlights. As in any market, competition benefits consumers when consumers are well informed. Within the higher education sector, the assumption of a well-informed consumer generally holds such that student choices, though not necessarily perfect, are better than those of central planners. The competition this creates encourages flexible institutional structures within the higher education sector and promotes adaptability to the prevailing economic and institutional environment. It is therefore important to promote competition and to better inform consumers where necessary so that these two dynamics reinforce each other.

Second, graduates should contribute to the cost of their degree so as to offer an allocative mechanism within the sector. Whilst higher education has large social benefits - albeit hard to quantify - it also has significant private benefits. Thus, it is both efficient and equitable that the graduate shares in the cost of higher education. 
But sharing costs should not be vested with spurious accuracy, as it is impossible to measure the positive externalities generated through education systems. Determining the optimal trade-off between public and private financing of an individual's higher education thus should be determined not by scientific quantification but rather in relation to a country's overall fiscal envelope and the incumbent political and social values. Third, as mentioned, conventional loans are the wrong model for investment in human capital. They lead to inefficiently low borrowing and lending. They are also inequitable, in that these efficiency problems impact most on people from poor backgrounds, and minorities, who might be less well informed and therefore less prepared to risk a loan, if able to obtain one.

These principles offer a number of lessons for the role of government in designing optimal financing strategies for higher education. The first is that there is sufficient cause for the provision of taxpayer support for higher education. The second is that the government must regulate the system, both through a maximum level of fees and by ensuring that there is effective quality assurance (the role of government is to make sure that quality assurance happens, not necessarily to provide the service itself). Third is that government can play a role in allocating incentives towards the needs of the economy-for example, providing larger subsidies for certain subjects. Last, the government should be focused on policies that at all times seek to widen participation and access to the higher education sector for all segments of society.

Governments are thus faced with a range of possibilities for how to finance higher education support schemes. The first is a mortage-type bank-loan system (as used in Canada, the United States and the Student Loans Fund in Thailand). This helps to solve the default problem for the lender as the government enters the market to guarantee the loan and it provides finance simply and easily. But there are costs. These include the large expenses for taxpayers when people default, and the credit of government often means that banks are less likely to make sure people pay their debt. Also, government is forced in to a strict rationing system to try to maintain costs. Because repayments are based on time, those who enter the workforce in a low-paying job or who have poor labourmarket outcomes at some stage will face a large repayment hardship, which could force default. There is also a credit risk for default for the students as it can ruin their credit rating and ability to finance into the future.

An increasingly popular option is the adoption of income-contingent loan schemes. Under this system, repayment is calculated as a portion of the graduate's (not student's) income in the future if and only if that graduate is earning over a threshold. This helps to fix the student default problem and lowers repayment hardships if the student enters a period of poor labour-market outcomes. These systems also act to smooth consumption over a person's life, as people pay more as their income goes up and less at times when income is low. 
In terms of collection methods, ideally, income-contingent repayments should be collected alongside income tax or social security contributions on the basis of a person's current earnings. Thus, repayments instantly and accurately reflect changes in a person's economic circumstances. This approach is, however, administratively demanding. A different approach-less optimal in policy terms, but less demanding administratively and hence perhaps more realistic in some countries - is to base a person's loan repayments on his or her last completed tax return. It is also important to recognise that the ideal recovery rate for loans need not necessarily be 100 per cent as these loans can also offer insurance against low lifetime earnings. In fact, there have been no cases where a country's income-contingent loan scheme collects 100 per cent repayments, and that is by design, as it is not optimal to have 100 per cent repayments.

Income-contingent loan schemes do, however, have a number of risks. For instance, students can avoid repayment by not earning enough income despite living in high-income households, or in some cases leaving the country. Also, in developing countries in particular, postgraduate incomes are often not high enough to have sufficient rates of repayment over the life of the scheme.

Of course, the overarching issue with income-contingent loan schemes relates to implementation. Regional and global experiences suggest that this issue has been the key cause of failure in many income-contingent loan schemes. These lessons must, for example, be carefully applied to the unique institutional and historical environment that categorises each East Asian economy. In particular, they must be designed in reference to the administrative capacity of the relevant country. For example, a country should not consider starting a loan scheme without a reliable method of identifying individuals and the capacity to maintain records of amounts borrowed, cumulative borrowing and interest charges, and the value of each person's repayments.

The strength of income-contingent loan schemes is that they provide support and allow for variation in outcomes of students and do not place an excessively high burden on their ability to repay in the event of a poor outcome at the end of their higher education. These schemes are, however, notoriously difficult to get right and the world and region are littered with examples of failed income-contingent loan schemes. This highlights the importance of carefully assessing the validity and details of implementing such schemes before they are carried out. Means-tested scholarships have, for example, proven very difficult to administer due to the difficulty of assessing the ability to pay sometimes exorbitant administrative costs, corruption and high rates of default. Indeed, the failure of systems in the Philippines and Thailand highlights these risks to the development of income-contingent loans that do not take into account the administrative limitations of their incumbent institutional environment. 
Once this is possible, the economics clearly points to the optimality of incomecontingent loan schemes. It is important to recognise, however, that a pure focus on higher education financing systems as a means of improving human-capital outcomes understates the importance of undertaking reforms that strengthen the fiscal arrangements for the bureaucracy as a whole. There is, for example, a strong interdependence between aggregate fiscal policy, expenditure processes and the ability of government to provide optimal support for higher education.

A further issue is that in some countries it will be optimal to have student grants from government operating in combination with income-contingent loans. A 100 per cent repayment rate for an income-contingent loan scheme as a whole is effectively a commercial loan with no subsidy from the government. The lower the repayment rate of an income-contingent loan scheme, the closer it becomes to a grant or direct wealth transfer. Therefore, countries with very low repayment rates have the option of simply giving grant transfers instead of running a poorly performing and costly income-contingent loan scheme. There is also scope for a combination of grants and income-contingent loans.

Before making a decision about which type of scheme is most suitable, it is necessary to take into account each country's institutional setting and the contexts of each market for implementation and ongoing success of any financing regime. Collection is an important aspect, with not all countries able to collect repayments effectively. Policy design that exceeds a country's implementation capacity is not appropriate policy.

It is also important to recognise that policy regimes of allowing foreign institutions into countries and the financing schemes of higher education institutions are intertwined. Questions of whether governments should subsidise foreignowned institutions, extend financing schemes to students of these institutions, and how these should be treated relative to domestic private-sector institutions are all complex issues that have not been adequately addressed in countries in the region yet.

\section{Regional Experiences}

Countries across the East Asian region have adopted a wide variety of approaches to financing their higher education sectors. There has also been a wide variety in both the successes and the failures of these approaches, which can offer a number of important lessons for the design of future strategies in the region and more broadly. In Chapter 4, Anthony R. Welch examines the rise of private higher education institutions and the implications for affordability and access in South-East Asia. 
The regional experiences are especially important in the context of education becoming a much more widely traded and internationally delivered service, with the movement across borders of students, academics and even institutions.

\section{Australia}

The introduction of the Australian Higher Education Contribution Scheme (HECS) in 1989 has been highly successful. HECS incorporates an incomecontingent loan for the payment of tuition through the income tax system, and was the first time that such an approach to student financing had been used internationally. A major issue for the adoption of HECS was the potential for the scheme to improve the access of the disadvantaged to Australian higher education, as private-sector lenders provide inefficient levels of loans given the uncertainty surrounding investments in human capital.

The intellectual architect of HECS, Bruce Chapman, explains the genesis and draws out the particular features of the Australian system in Chapter 5. There is evidence, as Chapman shows, to suggest that HECS has been associated with significant increases in the size of the higher education system and has proved to be administratively inexpensive. A major benefit of income-contingent loans in Australia is with respect to consumption smoothing for borrowers. For example, compared with the repayment of a similar bank loan, the burden of an income-contingent loan for students, as measured by the proportion of a graduate's income that is required to service the debt, can be far less than is the case for a bank loan. In addition, even though HECS means that students pay for a portion of their higher education — which had previously been freeextensive research into the implications of the scheme for the access of the poor to universities reveals that there have been no discernible effects. The second major impact of the HECS system is that for graduates receiving low incomes for some part of their lives there is considerable potential for the system to provide consumption smoothing. For situations in which former students experience very low incomes, the repayment of normal loans results in very high proportions of incomes being obliged to pay debt, and thus being unavailable for consumption. HECS has no such implication, and this is a critical benefit of an income-contingent loan.

\section{Japan}

In Chapter 6, Motohisa Kaneko takes a detailed look at higher education funding in Japan. Japan has been less successful than some places in the design and implementation of its higher education financing schemes despite undergoing radical changes over the past decade. For example, the Law for Incorporation of National University was enacted in 2004, transforming the legal status of the 
national universities as a kind of governmental facility to an independent legal entity. Private institutions have experienced a radical change in governmental subsidies, with their weight shifted from the mandatory current-cost subsidy to discretionary subsidies. In 2007, the current-cost subsidy fell from the previous year for the first time in 30 years. The government also revised the Private School Law to enhance accountability in governance and financing of private institutions. Yet, reforms are incomplete and the future institutional arrangements of the sector are uncertain.

There have been persistent demands for greater government expenditure on higher education, and one of the grounds for the argument was the low standing of Japan in international comparisons. On the other hand, there have been strong criticisms of this argument from the Ministry of Finance and various economic advisory committees. It is claimed that the low level of government expenditure does not constitute the main issue; after all, the government expenditure is financed by tax revenues - one of the main sources of which is taxes on individuals. Japan's higher education tends to be financed through direct contribution from households, not through tax and government expenditure. Whether this is optimal in Japan's case is part of an ongoing debate, and the international and regional experiences have not been brought to bear.

Japanese higher education is also faced with the effects of demographic change, a shrinking population and declining absolute enrolments. The direct consequence of the shrinking market will be the prospect of institutional closure. Some institutions are already facing a decline in applicants, and in a number of cases the freshman class has failed to fill the legal sitting capacity. The situation will be further aggravated over the next decade. Despite the large number of institutions in the high and medium-risk groups, there have been very few cases of closure for directly fiscal reasons. Many institutions appear to have sizeable margins in their current revenue over costs. Some of them have succeeded in slashing costs by either decreasing the number of employees or reducing wage levels. Nonetheless, the prospect of closure is definitely looming.

Kaneko makes clear that after a half-century of robust expansion, higher education in Japan is clearly at a crossroad. In order to respond to the new challenges, it has to undergo a significant transformation in which changes in financing assume the critical role. The policy management of a transition to fewer students has important implications for the Japanese higher education sector. Opening up further to international trade in education services is another issue that will have to be debated in addition to the improvements in the financial accessibility for prospective students. All of these developments involve a number of issues over which there are significant differences of opinion. In this sense, Japanese society is struggling to find a definite direction for higher education finance towards the future. 


\section{China}

The Chinese higher education sector has also been undergoing rapid transformation in recent years as the economy increasingly integrates itself into the global knowledge economy. The rapidly growing economy, increasing job opportunities and the demands of a modern society have resulted in large unmet student demand for financial assistance to attend higher education institutions in China - as measured by the gap between loan applications and approvals in the adoption of the country's student loan policy in 2004. In addition, the coverage of the financial assistance is very small across the sector and has declined in recent years. In total, the student loan coverage rate increased from 2.7 per cent of total students in 2004 to 6.6 per cent in 2005 but then dropped again, to 4.6 per cent, in 2006 .

The scale and pace of growth of the Chinese higher education sector are unprecedented and present policy makers with some acute challenges. Wei Jianguo and Wang Rong outline the problems and challenges in Chapter 7. At present, there are two major challenges to improving the effectiveness and size of the Chinese education sector. The first step is in defining the financial responsibilities of government for its elite and non-elite institutions. The second regards efforts that need to be made in the future to strengthen and improve the existing public higher education system or enhance the role of the nonpublic sector. Central to both of these challenges is improving China's student financial-aid system so that it can both channel the best students into the sector in a non-discriminatory way and provide adequate resources for the sector to remain competitive and meet the labour-market demands of the economy.

The State Council implemented a new policy for student financial aid in 2007. This policy allocated $\$ 7.1$ billion in earmarked funds annually to student financial aid (including aid for students in vocational middle schools). This has included a dramatic increase in the coverage of the National Scholarship Program to approximately 20 per cent of all students in the sector at approximately RMB2000 per recipient per annum.

In addition, in order to promote the development of the student loan program, the Ministry of Education, the Ministry of Finance, the People's Bank of China and the China Banking Regulatory Commission mandated a new policy for the student loan program in June 2004. This new policy both extended the repayment period of the loan, reducing repayment hardships, and allowed recipients to receive loan waivers if they voluntarily chose to work in less-developed regions or less-attractive professions for a set time after graduation. The new policy also reformed the way to identify banks that are eligible to provide student loans using bidding and implementing collaboration between the banks and higher 
education institutions to improve the competitiveness of the sector. Finally, it introduced a risk compensation fund, whereby the government and the higher education institution each pays 50 per cent of the fund to commercial banks.

The Chinese higher education sector still, however, faces a number of significant challenges in addressing the country's shortage of highly skilled labour, which can drive entrepreneurship and productivity into the future. As is the case in other countries, in China, the governance and accountability of the sector remain as the core determinants of whether the sector can adequately meet the needs of the country's rapidly growing economy. The government has made some significant moves towards decentralising the sector. For instance, since 1998, about 200 regular higher education institutions that used to belong to central ministries and agencies have been transferred to the jurisdiction of local governments. This has had a large impact, with the proportion of college enrolment in centrally controlled higher education institutions dropping from 20 per cent in 2000 to 10 per cent in 2006. There is, however, little evidence to suggest that locally run institutions perform any better or are more efficient than centrally controlled ones. Ultimately, setting up appropriate institutional structures that ensure that the sector remains accountable to the people it serves and adaptable to the changing demands of a rapidly growing economy will prove to be the biggest determinant of China's ability to meet its higher education needs.

\section{Indonesia}

Teguh Yudo Wicaksono and Deni Friawan outline in Chapter 8 the challenges the Indonesian higher education sector faces. Indonesian higher education institutions have expanded rapidly in the post-independence era (since 1945). In more recent decades, participation rates in higher education have, however, tended to stagnate. Access to tertiary education is also very unequal. In 2006, for example, the participation rate of students from the lowest 40 per cent income group was only 2.67 per cent, compared with about 33.9 per cent for the richest 20 per cent. In part, this is a result of a large share of the cost of higher education still being borne by parents and students as well as the flowon effects from low participation rates in secondary education. Notably, the percentage of national education expenditure to gross domestic product (GDP) increased from 2.4 per cent in 2001 to 3.8 per cent in 2007 , but this is still well below other countries in the region such as Malaysia (8.1 per cent) and Thailand (4.6 per cent). In addition, tertiary education received only less than 10 per cent of the total education budget - lower than primary education (75 per cent) and secondary education (15 per cent). 
In large part, the stagnation of access to higher education access stems from a number of failed attempts at financing arrangements in the sector. In the 1980s, student loans were implemented under the so-called 'Kredit Mahasiswa Indonesia' (KMI; Indonesian Student Loan) scheme, which provided government-backed loans to selected disadvantaged groups. After a few years, however, default rates reached up to 95 per cent and this scheme began to place an excessively high burden on government resources and was subsequently cancelled. This failure was caused largely by the moral hazard of the borrowers, a poor administration system and a lack of strong political support to impose more effective collection standards on students.

More recently, the government has sought to improve the funding of the sector by increasing resources for direct means-assessed scholarship paymentsparticularly to private higher education institutions, although public institutions are still the major beneficiaries. Even after being augmented with substantial private contributions, these scholarship programs were having an insufficient impact on the overall access of students to the higher education sector. In 2006, the Sampoerna Foundation in conjunction with the International Finance Corporation (IFC) and Bank International Indonesia (BII) also began to try to reinvent and rejuvenate the student loan program by offering advances of up to Rp200 million (approximately US\$20 000).

Perhaps the biggest constraint on the quality and access of Indonesia's higher education institutions, however, which cannot be corrected by student loan systems, has been the lack of proper long-term planning and vision for the sector. The universities suffer from internal inefficiency and poor initiatives, particularly in research, and lack clear lines of public accountability. Undoubtedly, these problems have brought negative impacts on quality, efficiency and the relevance of higher education in the country. The goals of widening access and improving the quality and quantity of higher education institutions are thus far from being achieved.

Facing these issues, the government, through the Directorate General for Higher Education (DGHE), has taken some major reform efforts. These have included moves to increase the autonomy of public university governance structures, clarifying funding mechanisms, particularly between private and public higher education institutions, as well as reforming the curriculum content so that it is more in line with the national development context. Ultimately, it will be the ability of these reforms to create an environment in Indonesia that allows the sector to make effective policy decisions that will determine whether the renewed financial loan scheme will prove a success or lead to another failure. 


\section{The Thai Case}

The last three chapters of the volume are concerned with the Thai case. The rapid expansion of the higher education sector in Thailand and the policy failures and successes make for valuable case studies. In Chapter 9, Somkiat Tangkitvanich and Areeya Manasboonphempool give an overview and outline the problems faced, the policy measures undertaken to date, and also assess the success and failure of each. Piruna Polsiri, Rangsit Sarachitti and Thitima Sitthipongpanich conduct analysis in Chapter 10 that shows repayment burdens for the Thai Student Loans Fund (SLF) under different scenarios of interest rate subsidies. Their chapter is a contribution to the understanding of the Thai case but also to the analysis of interest rate subsidies and repayment hardship in the higher education literature. Bruce Chapman and Kiatanantha Lounkaew in Chapter 11 compare alternatives in Thai income-contingent student loans.

Since the early 1900s, the number of higher educational institutions in Thailand has increased to nearly 800 institutions with the total number of students enrolled reaching 2.5 million. With a 41 per cent gross enrolment ratio, the country ranks second only to Japan and is ranked higher than much wealthier countries such as Malaysia and Hong Kong. The public sector plays a very dominant role in this education provision, enrolling more than four-fifths of total students.

To cope with this rapid enrolment expansion, the Thai education financing system has needed a number of reforms. During the past three decades, continued efforts have been made to transform major limited-admission public universities into autonomous universities. The purpose of this was to provide administrative flexibility to these universities, aiming to enhance their quality to an international level. So far, however, only seven public universities have been successfully transformed, with only a few more in the pipeline.

In addition to the direct provision of higher education by public institutions, the Thai government has also provided loans to students since 1996 under the SLF scheme. The main objective of the SLF is to increase the opportunities for students from low-income families to continue their study. Other objectives are to promote more equal income distribution in the long run and to develop a demand-side financing system by increasing the capacity of households to contribute more resources to education. The SLF loans cover tuition fees, educational-related expenses and other living expenses. Only high-school or tertiary-level students whose family's income is less than B150 000 per annum are eligible to apply for the loan. During the first 10 years of its operation, the SLF has lent to more than 2.6 million students, with the loan value totalling nearly B200 billion. 
In practice, however, despite its high cost, the SLF seems to have increased the educational opportunities of the borrowers only from families with income below the poverty line. Since this group constitutes only 13 per cent of the total borrowers, the income threshold set by the SLF appears to be far too high. The current SLF scheme also contains many flaws. For example, its loan-screening system is far from perfect, it fails to disburse loans on time, it has a very poor collection mechanism and it is still based on the supply-side financing paradigm. Analysis shows also that it has not significantly influenced the decisions of high-school students to continue their studies to a higher level, except for the poorest group, who were a minority among the recipients. In addition, the SLF is suffering from a serious financial sustainability problem due to its very low recovery rate.

The SLF was temporarily abolished and replaced with the Thai Income Contingent Allowance and Loan (TICAL) scheme under the Thaksin government in 2006with the SLF reintroduced following the 2007 election. The TICAL, which was modelled after the income-contingent loan scheme in Australia, is different from the SLF in many important ways. First, it allows only undergraduates but not high-school students to borrow. In addition, it sets no conditions on the household income of the borrowers. This means that all undergraduate students in any field may apply for a loan. Second, it covers only tuition fees, not other education-related and living expenses. Third, it does not require the borrowers to start repaying until their incomes reach B16 000 a month (the minimum income threshold for the payment of income tax). The repayment rate is contingent upon the borrowers' incomes, and is progressively increased with higher income. Fourth, there is no interest charged under the TICAL scheme, but the outstanding debt will be adjusted by inflation from the first year of borrowing. Finally, the revenue department is responsible for collecting the repayment.

The shift to the TICAL brought about many important improvements, especially a potentially more effective repayment collection system. Moreover, it was based on a demand-side financing paradigm that promoted more choices for students. The TICAL was not, however, without its problems; it still unnecessarily subsidised the borrowers by charging a zero real interest rate. In addition, the TICAL by itself could not bring about the overall changes to the educational financing system unless other complementary reforms were also undertaken.

Hidden costs in the SLF make up a large portion of the total implicit subsidy received by students. The Thai SLF is relatively soft in terms of payment hardships under poor post-education outcomes. It is also very generous in terms of the implicit subsidy. This means that a large amount of public money is required to maintain the system. If you remove a lot of the hidden benefits of the scheme, such as grace periods and income thresholds, the system becomes a 
lot more inexpensive but dramatically increases the burden on students. Having said this, the current scheme is prohibitively expensive for the Thai government and reform needs to be implemented whilst still maintaining widespread access to quality higher education for all economic groups.

Perhaps most importantly, policy certainty is a prerequisite for the longterm development of the system. Frequent policy reversals will not only bring about confusions to all stakeholders, they will also raise questions about the government's commitment to any loan programs, thus undermining the credibility and integrity of the scheme. Another important lesson is the importance of strengthening public financial management, which not only allows the government to implement a more effective higher education financing system, but also has a number of other equally important positive effects on the economy. Within this process, to avoid haphazard policy changes, policy makers should seek consensus from broad-based stakeholders before making any more major policy changes in the future.

\section{Conclusion}

Higher education and an appropriate financing system that helps to overcome market failures are essential components of a country's ability to integrate into the increasingly knowledge-based global economy.

The question is how to arrange the resources to make sufficient investment in education that is accessible to everyone while also improving the quality of the education that is delivered. This is not an easy problem particularly in the early stages of economic success when resources are stretched towards achieving many objectives. The focus of research is on the various strategies that have been used to promote the expansion of accessibility to higher education for the populations around the region. There is much policy experience in addressing these questions from other countries in the region and, taken together, these experiences can illuminate the challenges and options in different countries. The first of these is the ultimate role of government within the sector to correct a market failure that occurs from the existence of the large positive externalities derived from a highly educated, capable workforce. Large positive externalities lead to sub-optimal levels of investment in education under free-market conditions. This is also amplified by the inability of individuals to use human capital as collateral to make investments in their own education.

Such a situation creates a clear role for government to intervene in the higher education sector, but, as with all interventions, these must be carefully planned. One key element of this planning must be a clear recognition of what the government wishes to achieve from its intervention as this will play a large 
role in the optimal type of intervention. Ultimately, there are three main objectives of government intervention into the higher education sector. These include increasing the quantity and quality of and access to higher education. Consumption smoothing is an important aspect that helps facilitate this.

Economic theory also offers a number of lessons for the design of higher education schemes that can achieve the objectives of government. These include elements such as the importance of competition - both amongst universities and amongst those wishing to attend. This raises the importance of promoting access to the sector for people from all segments of society regardless of economic background.

It is also important for government to recognise the strengths and weaknesses of different types of support systems. Loan schemes are not well designed to directly benefit the poor. They are best designed to increase resources to the higher education sector and to provide an element of consumption smoothing, which will benefit mainly middle-income students. Grant-based or interest rate subsidy schemes, on the other hand, are better suited to improving access to higher education - particularly for poorer segments of society.

The big question is whether a country is capable of implementing and administering a student loan or higher education support scheme. Countries need a number of characteristics, such as strong political support, which is long term, enough bureaucratic capacity to ensure an effective administration as well as widespread public acknowledgment of the need for a higher education system.

It is also important to highlight the importance of country specificity in the design, implementation and, ultimately, the effect of higher education financing schemes. Israel attempted to import a scheme directly from another country without adjusting it to Israel's institutional settings with predictable adverse consequences. If Thailand were to implement a scheme similar to Australia's or New Zealand's it would be unlikely to generate either the same outcomes or the same level of debt repayment. One reason for this might be, for example, that local incomes are not high enough in Thailand to allow for sufficient rates of repayment. As noted in the previous section, the main policy conclusions of successes in the implementation of income-contingent loans across the region need to be handled with care. In some countries, the institutional framework might be currently inappropriate to allow efficient, even workable, collection of income-contingent loans. If this is the case, fruitful policy reform would seem to involve improvements in public-sector management. The Australian case, for example, offers some useful insights into the application of higher education financing in Thailand but should not be taken to suggest that income-contingent loans are a panacea to international higher education funding challenges. In many countries, there are important institutional difficulties to be overcome in the successful adoption of such approaches. 